\title{
GENERATION OF ACCENT IN \\ NOMINALLY PREMODIFIED NOUN PHRASES
}

\author{
RON ZACHARSKI \\ Department of Linguistics \\ University of Edinburgh \\ Edinburgh, UK
}

\begin{abstract}
${ }^{1}$
The primary purpose of this paper is to present a set of conditions that constrain accent placement in focused nominally premodified NPs. Selkirk (1984) argues that if the premodifier is an argument of the head, then the head can be deaccented. I agree with Selkirk's proposal and argue that what is essential is not whether the premodifier is a grammatical argument of the head noun, but rather, whether it is a $\theta$-complement in lexical conceptual structure. This proposal is evaluated by testing it against a corpus of naturally occurring data.
\end{abstract}

\section{0. introduction}

It is generally agreed that an utterance can be divided into two parts which are related to the discourse function of the information represented by that utterance. The TOPIC is what the sentence is about and the FOCUS represents a new predication about the ropic. This information structure constrains accent placement. For example, 'primary' accent must be within the constituent that represents the focused information. The ability of an accent on a single word to mark a larger phrase as focus is widely recognized. For example in (1) the accent on conservative can mark the phrase redneck conservative as the focused constituent (since (1) can be used to answer the question What was your town like?). (Accent is indicated by small caps and focus by underlining.)

\footnotetext{
${ }^{1}$ I would especially like to thank Jeanette Gundel and
} Nancy Hedberg for discussions and comments.
My hometown was redneck CONSERYSTTVE. (Lia Matera 1988 Smart Money)

In (1) focus is represented by a single constituent, but this need not be the case as (2) illustrates.

(2) A: Where's Kari?

B: SlluS drepped her off at SURDIKS.

In (2B), Kari, the referent of her, is the topic and the focus is thus discontinuous.

Though there seems to be agreement about the importance of a theory that accounts for the accent-focus relation, there is little agroement about the exact nature of this relationship. For instance, different theories give different answers to the question of whether this relationship is syntactic, semantic, morphological, or pragmatic. There is also disagreement over how large a phrase can be brought into focus by a single accent.

Even for simple constructions the relationship between accent and focus is unclear. In examples (3)-(7), a MODIFIER + NOUN constituent is focused. Note that in the (a) member of each pair, it is the modifier that receives the accent and in the (b) member of the pair, it is the head noun.

(3) a. Those are CRAwLING things.

b. Those are crawling INSECTS.

(Bolinger 1986.120)

(4) a. He has HUNTINGTON's discase.

b. He has Huntington's CHORFA. (Bolinger 1986.118)

(5) a. I do university RESEARCH.

b. I do CETACEAN research.

(6) a. (How do you know Franz? What was he to you?) He was my HISTORY teacher. 
b. (How do you know Franz? What was he to you??

He was my first-grade TEACHER.

(7) a. I work for the ROCKEFELLER Foundation.

b. I work for the Carnegie ENDOWMENT.

(Bolinger 1986.118)

This paper examines the association of accent and focus in nominally premodified NPs. ${ }^{2}$

\section{0 previous work.}

Pierrehumbert and Hirschberg (1990) state that some cases of the relationship between accent and focus seem clear. For example, when accent is on dress in the girl with the red DRESS the focus can be information represented by the noun dress, the NP the red dress, the PP with the red dress, or the entire NP the girl with the red dress. Whereas, accenting $R E D$ in the same phrase can serve only to focus information represented by the adjective red. However, regarding the relationship between accent and focus in general, they state that "The question of how an accent becomes associated with certain material is not yet well understood.' (p309 n.4)

Some researchers view this relationship between focus and accent as essentially syntactic. In the computational literature, Lyons and Hirst (1990) present the following rule constraining the accent focus relation:

(8) a. What is accented is necessarily in focus.

b. 'focus is optionally and nondeterministically percolated up the syntax tree, to any node from its rightmost daughter (rightmost because stress manifests itself only at the end of the focused constituent).' (1990.57)

Many theoretical linguists have proposed similar syntacric constraints relating phrasal accent placement and focus (see, for example, Chomsky and Halle 1968, Chomsky 1971, Jackendoff 1972, and Culicover and Rochemont 1983). However, as noted by these researchers, a rule like the one in (8b) makes incorrect predications for most nominally premodified NPs. For example, consider

\footnotetext{
21 use the more neutral term nominally premodified NPs instead of compounds.
}

the NP the history teacher in (9B) which has the structure presented in (10):

(9) A: What do you do?

B: I'm a HISTORY teacher.

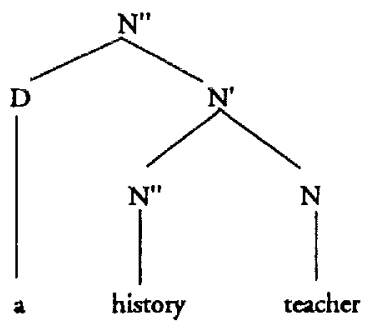

Clearly the NP a bistory teacher is the focused constituent. ${ }^{3}$ But by rule (8) the accent on bistory cannor serve to focus the entire NP since bistory is not the rightmost daughter of this phrase. 4 Thus, a phrasal rule such as (8b) cannot be operative in these cases. Instead, history teacher is viewed as a compound (as a structure of category $\mathrm{N}^{0}$ ) and accent is determined by a separate compound accent rule, which places stress on the leftmost element (sec Chomsky and Halle 1968, and Selkirk 1984).

Steedman (1991) claims that accent serves to divide an utterance into an optional constituent that represents the topic (what he, following Jackendoff 1972, calls the 'open-proposition') and 2 constituent that represents the focus. He argues that within each of these constituents, accent is put on the part that represents what is 'emphasized or contrasted' with something in the discourse context-the 'interesting part'. 'This idea has also been proposed by a number of other researchers (see, for example, Schmerling 1976, Gundel 1978, Selkirk 1984, Bolinger 1986, 1989, and Rochemont 1986). Although there is wide disagreement about the formal definitions of 'topicfocus' and 'the interesting part' there is no doubt that these are essential pragmatic determinants that constrain accent placement, and it is equally

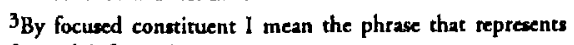
focused information.

${ }^{4}$ Rule $(7)$ also fails in a range of other cases including mosx intranaitive entences (What happened?-BUSH resigned). See Schmetling 1976, Gundel 1978, Bolinger 1986, and Lambrocht 1992 for further discussion.
} 
clear that they play a major role determining accent in nominally premodified NPs. Consider (11), a dialogue between two linguistics professors about the dissertation of a student in the department:

(11) A: What's the disscrtation about?

$B$ : Something to do with language ACQUISITION.

$$
\text { (=Ladd } 1980.90 \text { ex.48) }
$$

Ladd (1980) notes that when linguistics professors are talking about a dissertation of a student in the department, they assume that the dissertation is about some aspect of language and language can be deaccented. Ladd continues 'Bur the linguist's proud parents, who are not linguists, would tell their friends, who are also not linguists, that their son's dissertation was about LANGUAGE acquisition.' (Ladd 1980.90)

It could be argued that the accent patterns in (3)-(5) are also determined by 'interestingness'. However, the role of 'interestingness' is less clear in phrases like those in (6) and (7). As Bolinger (1989.200) notes, accent placement in some prenominally modified NPs is more invariable than in others. For example, while in (12) the old information constrains the the location of accent, this is not the case in (13) and (14)

(12) a. My research is on language-

Particularly on language ACQUISITION. \#Particularly on LANGUAGE acquisition.

b. My research is on acquisition$\left\{\begin{array}{c}\text { \#Particularly on language ACQUISITION. } \\ \text { Particularly on LANGUAGE acquisition. }\end{array}\right\}$

(13) June hold a singular place in the study of insects.

\{JUNE bugs can be seen.

\{??June BUGS can be seen.

(14) As we were travelling along the road we came to a $\left\{\begin{array}{c}\text { ROADblock. } \\ \text { \#roadBLOCK. }\end{array}\right\}$ (= Bolinger 1989.216)

The fixed stress on the initial syllables serves to mark the phrase as a unitary concept rather than a compositional one. However, not all NPs representing unitary concepts receive leftward stress (for example, buman Being).

\section{2. argument structure and accent}

What then governs the location of accent in nominally premodified NPs? Why, for example, does He was my bistory TEACHER sound odd as an answer to the question How do you know Franz? What was be to you? Selkirk (1984) suggests a particularly compelling answer. She presents the two constraints in (15) and (16).

(15) Basic Focus Rule

A constituent to which a pitch acoent is assigned is a focus.

(1984.207)

\section{(16) Phrasal Focus Rule}

A constituent may be in focus if (i) or (ii) (or both) is true:

$i$. 'The constituent that is its bead is a focus.

ii. A constituent contained within it that is an angument of the head is a focus

(1984.207)

The Basic Focus Rule in (15) is mandatory. This rule states that every word that contains an accent is necessarily focused. The phrasal focus rule given in (16) is optional. The rule (16i) states that if a head is a focused constituent, then any projection of that head can optionally be focused. If I say

(17) Victoria visits BONEyards

the $\mathrm{N}$, boneyards, is necessarily a focused constituent by rule (15). Rule (16i) permits focus to percolate to the projections $\mathrm{N}^{\prime}$ and $\mathrm{N}^{\prime \prime}$ as shown in (18):

$$
\begin{aligned}
& \text { Victoria visits }[\mathrm{N} ":+ \text { focus }[\mathrm{N} ;+ \text { focus } \\
& \text { [N:+focus [BONEyards]]] }
\end{aligned}
$$

Rule (16ii) states that if an argument of a head is focused, and if that focused constituent is conrained within the maximal projection of that head, then the projection of that head can be focused. For example, if I say

(19) Ann danced the tarantel.

the $N$, tarantella, is necessarily a focused constituent. Since this $N$ is the head of the $N^{\prime \prime}$, the tarantella, by rule (16i) the tarantella can be a focused contituent. "This $\mathrm{N}^{\prime}$ is an argument of the $v$, danced, and is contained within the maximal 
projection of that V. Thus, the VP can be a focused constituent by rule (16ii). This leads to correct results since this utterance can be used to respond to the question What did Ann do at the party? (She [v": + focus danced the taranTELla.])

Selkirk's theory of prosody-focus relation predicts the following accent patterns in focused modifier-noun constructions:

(20) Selkirk's predictions concerning modifier-noun pairs

ARGUMENT head

ARGUMENT HEAD

adjunct HEAD

*argument HEAD

ADJUNCT HEAD

*ADJUNCI head

Thus, if a noun phrase represents focused information, and if that noun phrase consists of an argument followed by the head noun, then the prediction is that the argument is necessarily accented. This seems like an elegant way to characterize the difference between leftward and rightward accented prenominally modified noun phrases, which has been problematic for other approaches to accent placement. Consider, for example, the difference in accent pattern between (21) which has an accent on its left constituent, and (22) which has the accent on its right constituent.

\section{HISTORY teacher}

student TEACHER

Selkirk's theory offers a straightforward explanation of this difference. History is an argument of teacher in (18) and thus by rule (13ii) representation of the entire noun phrase can be focused. However, in (19) student is an adjunct and accenting the head, teacher, is required to focus the representation of that noun phrase. A similar notion has been suggested by Rochemont (1986) as shown in (23). (See Rochemont 1986 for 2 discussion comparing his focus rules to those of Selkirk 1984.)

(23) 2. If $\alpha$ is $[+$ focus $]$ and $\alpha$ is $X^{0}$, then $X^{n}$ is [+focus].

b. If $\alpha$ is [+focus] and $\alpha$ is an argument of $\mathrm{X}^{0}$ contained in $\mathrm{X}^{\mathrm{n}}$, then $\mathrm{X}^{0}$ is [+focus].

c. If $X^{0}$ is [+focus] and $\alpha$ is an adjunct of $\mathrm{X}^{0}$ then $\alpha$ is [+focus].

There are three possible relations between a prenominal NP and its head. The prenominal can be a grammatical argument, a complement in lexical conceptual structure, or an adjunct modifier. A distinguishing characteristic of an adjunct modifier is that it is licensed by predication. ${ }^{5}$ As a result, it can be separated from its head by a copula. For example, in the phrase the red car, red is an adjunct modifier and can be separated from its head as (24) illustrates.

(24) The car is red.

In (22) student is a modifier and can be separated from its head as in

(25) The teacher is a student.

However, in (21) history is not a modifier and it cannot be separated from its head as (24) shows.

(26) ??The teacher is of history.

There is one question that immediately comes to mind: is Selkirk's notion of 'argument' a syntactic notion (that is, is it a grammatical argument licensed by $A$-structure), or is it a semantic notion involving $\theta$-participants in los?

\section{2. arguments}

Grimshaw (1990) argues convincingly that only nouns that have an internal aspectual analysis (nouns that refer to what she calls complex events) have argument structure (A-structure). She describes significant differences in the behavior of complex event nouns and other nouns to support this analysis. For example, complex event nominals have obligatory arguments as shown in (27)

(27) a The assignment is to be avoided.

b. "The constant assignment is to be avoided.

c. The constant assignment of unsolvable problems is to be avoided.

(Grimshaw 1990.50 ex.8)

Grimshaw considers assignment to be ambiguous between a complex event interpretation and a process interpretation. The addition of the modifier constant forces the complex event interpretation since constant can only be construed as a modifier of assignment on the complex event reading. Thus, it's A-structure must be satisfied as in (27c) just as

5That is, the meaning of modifier is predicated on the external argument of the head noun (Its $R$ argument). 
the A-structure of the verb assign must be satisfied as in (28).

(28) a We constantly assign problems. c. "We constantly assign. (Grimshaw 1990.50 ex.8)

If Grimshaw's analysis is correct, as I believe it is, then the argument referenced in Selkirk's Phrasal Focus Rule, is best not construed as an argument in A-structure. For while rule (16) would make correct predictions regarding complex event nominals such as those illustrated in (29), it fails on nominals that do not represent complex events as in (30)

$$
\begin{aligned}
& \text { (29) a. TRUE felling } \\
& \text { b. COOKIE baking } \\
& \text { (30) a. HISTOKY teacher } \\
& \text { b. BIT guzzler }
\end{aligned}
$$

I believe the distinction is a senuantic one involving $\theta$-participants in lexical conceptual structure (lcs). Every verb and noun (including deverbal nouns) has a lexical conceptual structure that includes the entities involved in the events or states described (see, for example, Dowty (1989), Fillmore (1968), and Jackendoff (1987, 1990)). Selkirk's intuitions expressed in rules (15) and (16) are essentially correct. Reformulating her rules as constraints between lexical conceptual structure and focused information offers a more precise characterization of her insights. A reformulation of (15) and (16) constraining the accent-focus relation of premodified NPs containing a deverbal element is given in (31) and (32):

(31) The representation of a constituent is focused if that constituent receives a pitch accent.

A representation, $R$, may be focused if a representation that is a $\theta$-complement of $R$ is focused.

Consider the pairs in (33) and (34).

$$
\begin{aligned}
& \text { (33) a. PACKAGE delivery } \\
& \text { b. overnight DELIVERY } \\
& \text { (34) a. CETACEAN research } \\
& \text { b. university RESEARCH }
\end{aligned}
$$

According to Grimshaw, neither delivery nor research has an A-structure since neither has an internal aspectual analysis. However, since these are both deverbal nouns, they inheric their $\theta$-structure from the related verbs. Package, then, is a $\theta$-complement of delivery, since package is the theme of deliver, (He delivers packages). Thus delivery can be deaccented as in (33a). However, in (33b), ovemight is not a $\theta$-complement of delivery $\left(^{*} H e\right.$ delivers overisight) and thus delivery must be accented. Likewise, in (34a) cetacean is the theme of research (He researches cetaceans) and thus research can be deaccented. However, in (34b) university is

\begin{tabular}{|c|c|c|c|}
\hline $\begin{array}{l}\text { modifier's re } \\
\text { lation to head }\end{array}$ & $\begin{array}{l}\text { accent on } \\
\text { left el- } \\
\text { ement }\end{array}$ & $\begin{array}{l}\text { accent on } \\
\text { right el- } \\
\text { ement }\end{array}$ & totals \\
\hline$\theta$-argument & 115 & 11 & 126 \\
\hline $\begin{array}{l}\text { not- } \\
\theta \text {-argument }\end{array}$ & 2 & 18 & 20 \\
\hline totals & 117 & 29 & 146 \\
\hline
\end{tabular}
not a $\theta$-complement of resedrch and research must be accented.

The rules presented in (31) and (32) were tested on data collected from multiple genres of natural discourse including public radio news articles, multiple participant discussions, and academic lectures. The results are given in Table 1

As shown in this table, the rule makes correct predictions in approximately $90 \%$ of the cases. The rule predicts that if the modifier's relation to head is a $\theta$-complement, then the accent should be on the left element-the complement. This was indeed true for 115 instances. Some examples are given in (35) and (36).

(35) Why should I buy one of those POTATo twaddlers (that can makc potato rossettes simply and easily and cumes with 1 free set of Ginso knives?)

(36) a FEMINIST bashing

a. LANGUAGE users

b. PUB crawlers

c. COMPUTER makers

d. TEAK trade

e. CONSISTENCY checkers 
The rule also predicts that if the modifier is not a $\theta$-complement of the head then the head needs to be accented. That was the case for 18 of the 20 instances in the data. Examples of this are given in (37) and (38)

She and her sister RAPPERS never stop TELLING each other to be PROUD of what they ARE, to have RESPECT for themselves and the culture they COME from.

(38) a. amateur WRITER

b. woman HIPHOPPERS

c. continuation COVERAGE

e. last-minute FILER

There were $11 \theta$-complement instances that were counterexamples to the rule presented in (32). Some examples of this are presented in (39).

(39) a. government ENCOURAGEMENT

b. systems ANALYST

c. tenant BLACKLISTING

d. human INTERVENTION

e. relationship DEPENDENCY

At present I have no explanation as to why these are accented the way they are. Why, for example, is one problem referred to as DRUG addiction and another as relationship DEPENDENCY?

\section{3. agents and experiencers}

The accent characteristics of phrases where the nominal premodifier can be construed as a subject of the head is less clear. There is some controversy as to whether such constructions are possible. For example, Selkirk (1982.34) restricts subjects from occurring in these compounds by use of the rule presented in (40)

(40) The SUBJ argument of a lexical head may not be satisfied in compound structure.

Sproat and Liberman (1987) point out that subjects in compounds are not usually accented. The examples they give are presented in (41)

(41) a. woman SWIMMER

b. child DANCING

c. student DEMONSTRATION

Sproat and Liberman 1987.143
However, I suggest that woman in (412) is not 2 complement of swimmer. Woman SWIMMER is an appositional compound (similar to helicopter GUNSHIP). Appositional compounds are lists of propositions, and like all lists, the last element of the list typically receives the main accent. Some evidence to support this view that (41a) is appositional is that the prenominal can be separated from the head by a copula as in (42)

(42) The swimmer is a woman.

Following Booij and van Hafften (1988) I believe that a semantic effect of -er affixation is to bind the agent or experiencer in lcs. Thus, the agent role is not available to the representation of woman and that representation must be linked by $\theta$-identification. Other examples of this type include (36) and $(37 a 8 \mathrm{bb})$. In cases were the nonhead is the agent of the head the accent pattern varies-sometimes the head receives the accent (as (39a), (41b), and (41c)) and at other times the nonhead receives the accent as in (43). ${ }^{6}$
(43) a. DOG bite
b. BEE sting
c. Cock fighting

\section{4. discussion}

Deverbal nouns head $25 \%$ of the nominally premodified NPs in the corpus examined. 7 Since deverbal nouns are distinguished from other nouns in the lexicon, the generation system can correctly determine when to apply the rule in (32). As Dowty (1989), Jackendoff $(1987,1990)$ and others have noted, lexical conceptual structure is needed for correct semantic interpreration. (For computational approaches see Charniak (1981), Dorr (1989), and Sowa (1991).) Thus, the rule requires only information that has independent motivation for being in the lexicon.

As Selkirk noted, the same factors that govern accent placement in these constructions also constrain accent in verb phrases and sentences. In both cases the semantic interpretation of a head can be focused if its $\theta$-complement is focused.

\footnotetext{
${ }^{6}$ This variation in accent is also seen in agents realized as possessives.

${ }^{7}$ Deverbal in the sense that they inherit the las of a related verb. They do not necesserily have A-structure (other than the external sole for nouns).
} 
The same rules ((31) and (32)) are operative. Thus accenting potatoes in John twaddles POTATOES can serve to focus the representation ( $x$ twaddles potatoes) and similarly, accenting potato in POTATO twaddler focuses the representation (the $x$ such that ( $x$ twaddles potatoes)).

A central question in the study of intonation is what factors govern accent placement. I have argued here that argument structure plays no role in this determination at least as to prenominally modified noun phrases and have shown how a theory of focus like the one presented in Selkirk 1984 can be refined to account for semantic constraints for accent placement.

\section{References}

Bolinger, Dwight. 1986. Intonation and its parts. Stanford: Stanford University Press.

Bolinger, Dwight. 1989. Intonation and its uses. Stanford: Stanford University Press.

Booij, Geert and Ton von Haaften. 1988. The external syntax of derived words: evidence from Durch. Yearbook of Morphology, ed. by Geert Booij and Jaap van Marle. 29-44.

Charniak, E. 1981. 'The casc-slot identity theory. Cognitive Science 5.285-292.

Chomsky, Noam. 1971. Deep structure, surface structure, and semantic interpretation. Semantics. Ed. by R. Jacobs and P. Rosenbaum. 183-216. Cambridge: Cambridge University Press.

Chomsky, Noam and M. Halle. 1968. The sound pattern of English. New York: Harper and Row.

Culicover, Peter, W. and Michael Rochemont. 1983. Stress and focus in English. Language 59(1):123-165.

Dorr, Bonnie. 1989. Lexical conceptual structure and generation in machine translation. Proceedings of the Annual Meeting of the Cognitive Science Sociery 9.

Dowty, David R. 1989. On the semantic content of the notion of 'thematic role'. Properties, types, and meaning, ed. by Gennaro Chierchia, Barbara H. Partee, and Raymond Turner.

Fillmore, Charles. 1968. The case for case. Universal in linguistic theory, ed. by E. Bach and R. Harms. New York: Holt, Rinehart, and Winston.

Grimshaw, Jane. 1990. Argument Structure. Cambridge, MA: MIT Press.
Gundel, Jeanette Kohn. 1978. Stress, Pronominalization and the given-new distinction. University of Hawaii Working Papers in Linguistics. Department of Linguistics, University of Hawaii, Honolulu.

Jackendoff, Ray S. 1972. Semantic interpreration in generative grammar. Cambridge, MA: MIT Press.

Jackendoff, Ray S. 1987. 'The status of thematic relations in linguistic theory. Linguistic Inquiry 18.369-411.

Jackendoff, Ray S. 1990. Semantic structures. Cambridge MA: MIT Press.

Ladd, D. Robert. 1980. The structure of intonational meaning. Bloomington: Indiana University Press.

Lambrecht, Knut. 1992. Sentential-focus structures as grammatical constructions. Paper presented at the Annual Meeting of the LSA.

Lyons, Daniel, and Graeme Hirst. 1990. A compositional semantics for focusing subjuncts. Proceedings of the Annual Meeting of the Association for Computational Linguistics. 28.54-61.

Pierrehumbert, Janet, and Julia Hisrchberg. 1990. The meaning of intonational contours in the interpretation of discourse. Intentions in communication. Ed. by P. R. Cohen, J. Morgan and M. E. Pollack. 271-311. Cambridge, MA: MIT Press.

Rochemont, Michael S. 1986 . Focus in generative grammar. Ansterdam: John Benjamins.

Schmerling, Susan F. 1976. Aspects of English sentence stress. Austin: University of 'Texas Press.

Selkirk, Elisabeth. 1982. The syntax of words. Cambridge MA: MIT Press.

Selkirk, Elisabeth. 1984. Phonology and syntax. Cambridge MA: MIT Press.

Sowa, John. 1991. Logical structures in the lexicon. Proceedings of a Workshop speonsored by the Special Interest Group on the Lexicon of the Association for Computational Linguistics. 38-55.

Sproat, Richard W. and Mark Y. Liberman. 1987. Proceedings of the Annual Meeting of the Association for Compurational Lingustics. 25.140-146.

Steedman, Mark. 1991. Structure and intonation. Language 67.260-296. 